\title{
The Distribution of eIF4E-Family Members across Insecta
}

\author{
Gritta Tettweiler, ${ }^{1,2}$ Michelle Kowanda, ${ }^{1}$ Paul Lasko, ${ }^{1}$ \\ Nahum Sonenberg, ${ }^{2}$ and Greco Hernández ${ }^{3}$ \\ ${ }^{1}$ Department of Biology, McGill University, 1205 Dr. Penfield, Montreal, QC, Canada H3A 1B1 \\ ${ }^{2}$ Department of Biochemistry and Goodman Cancer Research Center, McGill University, Montreal, QC, Canada H3A 1A3 \\ ${ }^{3}$ Division of Basic Research, National Institute for Cancer (INCan), Avenida San Fernando No. 22, Tlalpan, \\ 14080 Mexico City, DF, Mexico \\ Correspondence should be addressed to Greco Hernández, ghernandezr@incan.edu.mx
}

Received 31 December 2011; Accepted 14 March 2012

Academic Editor: Armen Parsyan

Copyright (๑) 2012 Gritta Tettweiler et al. This is an open access article distributed under the Creative Commons Attribution License, which permits unrestricted use, distribution, and reproduction in any medium, provided the original work is properly cited.

\begin{abstract}
Insects are part of the earliest faunas that invaded terrestrial environments and are the first organisms that evolved controlled flight. Nowadays, insects are the most diverse animal group on the planet and comprise the majority of extant animal species described. Moreover, they have a huge impact in the biosphere as well as in all aspects of human life and economy; therefore understanding all aspects of insect biology is of great importance. In insects, as in all cells, translation is a fundamental process for gene expression. However, translation in insects has been mostly studied only in the model organism Drosophila melanogaster. We used all publicly available genomic sequences to investigate in insects the distribution of the genes encoding the cap-binding protein eIF4E, a protein that plays a crucial role in eukaryotic translation. We found that there is a diversity of multiple ortholog genes encoding eIF4E isoforms within the genus Drosophila. In striking contrast, insects outside this genus contain only a single eIF4E gene, related to D. melanogaster eIF4E-1. We also found that all insect species here analyzed contain only one Class II gene, termed $4 E-H P$. We discuss the possible evolutionary causes originating the multiplicity of eIF4E genes within the genus Drosophila.
\end{abstract}

\section{Introduction}

Insects are the most diverse animal group on Earth and comprise over half of all extant described species, dominating thus all terrestrial ecosystems [1-4]. Winged insects were the first organisms that evolved controlled flight, some 120, 200, and 300 million years (Myr) before flying reptiles, birds, and bats, respectively. Indeed, wings are believed to have led largely to the spectacular diversification of insects because they were able to explore and invade all terrestrial ecosystems, escape predators, and exploit scattered resources $[2,5]$. Many studies show that insect diversity has been also strongly shaped by other evolutionary and ecological processes, including their relative ancient geological age, low extinction rate, ecological niches occupancy, sexual selection, and sexual conflict [1].

Insects originated 434-421 Myr ago during the Silurian Period, and it is suggested that earliest terrestrial faunas already included wingless insects $[2,5,6]$. Indeed, the aquatic-terrestrial transition of insect ancestors is associated with the earliest vascular land plants fossils. Thus, it is thought that true insects evolved from an aquatic arthropod that formed an ecological association with the earliest vascular plants and subsequently both lineages coevolved $[2,6]$. By the Permian (299-251 Myr ago) nearly all extant insect orders already have emerged, and later a second spectacular radiation happened in the Jurassic. Insects have been diverging ever since $[2,7,8]$. Winged insects, which account for more than $98 \%$ of the class Insecta, emerged when early arborescent plants evolved (pteridophytes, mostly ferns, and horsetails) $380-354 \mathrm{Myr}$ ago (during the Devonian). It is hypothesized that insect flight arose as an adaptation to the increasing height of trees, and that a number of highly successful insect species coevolved with flowering plants $[2,5,6,9]$.

Besides their crucial ecological importance in all terrestrial ecosystems, insects have a huge direct impact in all aspects of human life and economy. In agriculture, some 
species cause huge damage to crops (e.g., aphids and weevil beetles), whilst others are of great benefit to flowering plants, which depend on pollinating species (e.g., bees, wasp, and butterflies). There are many species that can spread human pathogens (e.g., mosquitoes, fleas, and bed bugs) as well as key model organisms for basic research (Drosophila). Furthermore, several species serve as research objects for social behavior studies (e.g., bees and ants). Because of their overall significance, for many years immense efforts have been put forward to studying all aspects of insect biology. However, many biological processes, including translation, are still poorly studied at the molecular level. Therefore, further characterization of insect translation is necessary.

Most eukaryotic mRNAs are translated by a capdependent mechanism, whereby the mRNA is recruited to the ribosome through recognition of the $5^{\prime}$ cap structure $\left(\mathrm{m}^{7} \mathrm{GpppN}\right.$, where $\mathrm{N}$ is any nucleotide) by the cap-binding protein eIF4E in complex with the scaffold protein eIF4G and the RNA helicase eIF4A $[10,11]$. Three-dimensional studies demonstrated that eIF4E associated to cap-analogues resembles "cupped-hands" in which the cap structure is stacked between two highly conserved tryptophan residues (Trp-56 and Trp-102 of mouse eIF4E) through $\pi$ bond interactions. A third conserved tryptophan residue (Trp-166 of mouse eIF4E) binds the $\mathrm{N}^{7}$-methyl moiety of the cap structure [1215]. Due to its pivotal role in translation, eIF4E activity is tightly regulated. Perhaps the most prominent regulatory mechanism is performed by eIF4E-binding proteins (4EBPs), which bind eIF4E via an eIF4E-binding motif that is shared with eIF4G. 4E-BPs act as competitive inhibitors of eIF4E-eIF4G interaction and therefore of translation [10, $16,17]$. Another mechanism regulating eIF4E activity in some metazoans, including human, Drosophila, and Aplysia, is by phosphorylation of Ser-209 (mouse protein numbering; Ser251 in Drosophila eIF4E-1) [18-20].

Among insects, the unique translation initiation machinery that has been studied thus far is that from $D$. melanogaster. This species possesses seven genes encoding eight eIF4E cognates, one of them being 4E-HP (eIF4Ehomolog protein) $[19,21-27]$. All residues involved in $5^{\prime}$ cap structure binding are conserved in all eIF4Es [2226], and experimental evidence confirmed their ability to bind this structure $[21,24,26]$. Likewise, most residues involved in eIF4G and 4E-BP binding are conserved and yeast two-hybrid experiments showed that all of them, except for eIF4E-6 and 4E-HP, interact with both proteins [26]. A functional assay showed that D. melanogaster eIF4E-1, eIF4E-2, eIF4E-4, eIF4E-5, and eIF4E-7, but not eIF4E3 and eIF4E-6, are able to phenotypically rescue a lethal eIF4E-deficient yeast strain [26]. eIF4E-1 loss-of-function mutations cause growth arrest, severe embryonic defects, and lead to embryonic lethality [19,28-30], and phosphorylation of eIF4E-1 at Ser251 is necessary for growth of the whole organisms [19]. Evidence supports the idea that there is physiological specialization of eIF4E cognates. While global translation is performed by eIF4E-1 $[19,28]$, eIF4E-3 is a testis-specific factor promoting translation in this tissue [31], eIF4E-5 might be involved in autophagy [32] and 4E-HP is a translational repressor $[27,33,34]$. Moreover, other activities have been reported for eIF4E-1, including a role in neurogenesis $[35,36]$ and a nuclear role in splicing [37]. Interactions of eIF4E-1 with different proteins, including $4 \mathrm{E}-$ BP [26, 38], Cup [39], Diap1 [40], and Ago2-Risc complex [41], have been described. Additionally, 4E-HP was found to interact with the RNA helicase Belle [42].

Recent advances in sequencing technology allow comparative analysis of multiple genomes across a wide range of evolutionarily related species. Thus, gene and protein annotation of twelve different Drosophila species [43] and from other insect species $[44,45]$ are now available. Here we investigated the distribution of the cap-binding proteins eIF4E and 4E-HP across the class Insecta.

\section{Material and Methods}

We compared annotated protein sequences of insects eIF4Efamily members obtained from all publicly accessible databases, that is, http://umbicc3-215.umbi.umd.edu/ [45] and from several sequencing projects available in the NCBI GenBank NR, http://flybase.org/ and in http://www .butterflybase.org/ [44]. The genomes analyzed were from 12 Drosophila species [43], Aedes aegypti, Anopheles gambiae (all Diptera), Camponotus floridanus, Harpegnathos saltator, Apis mellifera, Nasonia vitripennis (all Hymenoptera), Tribolium castaneum (Coleoptera), Manduca sexta, Spodoptera frugiperda, Heliconius melpomene, Bombix mori, Papilio xuthus (all Lepidoptera), and Acyrthosiphon pisum (Hemiptera). Table 1 shows all annotated genes and the proteins they encode that were analyzed in this study. Incomplete sequences and sequences encoding partial putative proteins were excluded. Amino acid sequences were aligned using ClustalW [46, 47] with the Biology Workbench bioinformatics package and improved by eye. Phylograms were assembled by neighbor-joining using MEGA5 program [48].

Jagus and colleagues proposed a classification of eIF4Es from 230 species into three classes according to variations in the residues Trp-43 and Trp-56 (human eIF4E numbering) $[45,49]$. Class I members contain both Trp residues; Class II members contain Tyr, Phe, or Leu at the first position and Tyr or Phe at the second position; Class III proteins contain Trp at the first position and Cys or Tyr at the second position $[45,49]$. In the present study we will follow this classification. Since D. melanogaster is one of the most characterized model organisms and thus the best-studied species of all insects (whose entire genome is available for over a decade now (http://flybase.org/ [50]), and because among insects only eIF4Es and 4E-HP from $D$. melanogaster have been characterized $[19,21-42]$, we chose D. melanogaster eIF4Es sequences, numbering and nomenclature (http://flybase.org/ $[25,26])$ as a reference. To avoid misunderstanding with another nomenclature $[45,49]$, here we will keep the fly database (http://flybase.org/) nomenclature, referring when necessary, to the Class each eIF4E belongs to.

\section{Results and Discussion}

3.1. eIF4E Proteins across the Genus Drosophila. Gene duplication of eIF4E is particularly striking in D. melanogaster 
TABLE 1: Overview of annotated genes analyzed in this study.

\begin{tabular}{|c|c|c|}
\hline eIF4E paralogs within D. melanogaster. & Orthologs in other Drosophila species & Orthologs in other insects \\
\hline \multirow{11}{*}{ eIF4E-1/2 (CG4035) } & D. simulans GD12928 & A. aegypti AAEL001916 \\
\hline & D. sechellia GM24878 & A. gambiae AGAP007172 \\
\hline & D. erecta GG14044 & C. floridanus EFN73765 \\
\hline & D. yakuba GE21247 & H. saltator EFN83757 \\
\hline & D. ananassae GF23736 & A. mellifera XP_624290.2 \\
\hline & D. willistoni GK20927 & T. castaneum XP_973494 \\
\hline & D. pseudoobscura GA28658 & M. sexta MSP00767 \\
\hline & D. persimilis GL12850 & S. frugiperda AAK 94897 \\
\hline & D. virilis GJ13832 & B. mori BGIBMGA012674 \\
\hline & D. grimshawi GH16860 & H. melpomene HMP00347 \\
\hline & & A. pisum ACYPI001956 \\
\hline \multirow{10}{*}{ eIF4E-3 (CG8023) } & D. simulans GD14067 & \\
\hline & D. sechellia GM25034 & \\
\hline & D. erecta GG14292 & \\
\hline & D. yakuba GE20721 & \\
\hline & D. ananassae GF25106 & \\
\hline & D. willistoni GK17185 & \\
\hline & D. pseudoobscura GA24628 & \\
\hline & D. persimilis GL26506 & \\
\hline & D. virilis GJ12520 & \\
\hline & D. grimshawi GH15498 & \\
\hline \multirow{11}{*}{ eIF4E-4 (CG10124) } & D. simulans GD13118 & \\
\hline & D. sechellia GM13832 & \\
\hline & D. erecta GG15032 & \\
\hline & D. yakuba GE20475 & \\
\hline & D. ananassae GF10894 & \\
\hline & D. willistoni GK12583 & \\
\hline & D. pseudoobscura GA28599 & \\
\hline & D. persimilis GL13241 & \\
\hline & D. virilis GJ12668 & \\
\hline & D. grimshawi GH15637 & \\
\hline & D. mojavensis GI12684 & \\
\hline \multirow{11}{*}{ eIF4E-5 (CG8277) } & D. simulans GD14038 & \\
\hline & D. sechellia GM25004 & \\
\hline & D. erecta GG14453 & \\
\hline & D. yakuba GE21642 & \\
\hline & D. ananassae GF10327 & \\
\hline & D. willistoni GK17737 & \\
\hline & D. pseudoobscura GA28380 & \\
\hline & D. persimilis GL18042 & \\
\hline & D. virilis $\mathrm{GJ} 13889$ & \\
\hline & D. grimshawi GH14978 & \\
\hline & D. mojavensis GI13141 & \\
\hline \multirow{4}{*}{ eIF4E-6 (CG1442) } & D. simulans GD18002 & \\
\hline & D. sechellia GM12271 & \\
\hline & D. erecta GG12044 & \\
\hline & D. yakuba GE10483 & \\
\hline
\end{tabular}


TABLe 1: Continued.

\begin{tabular}{|c|c|c|}
\hline eIF4E paralogs within D. melanogaster. & Orthologs in other Drosophila species & Orthologs in other insects \\
\hline \multirow{8}{*}{ eIF4E-7 (CG32859) } & D. simulans GD16435 & \\
\hline & D. sechellia GM18997 & \\
\hline & D. erecta GG12718 & \\
\hline & D. yakuba GE16544 & \\
\hline & D. ananassae GF22031 & \\
\hline & D. willistoni GK16243 & \\
\hline & D. virilis $\mathrm{GJ} 16331$ & \\
\hline & D. mojavensis GI14982 & \\
\hline \multirow{11}{*}{$4 E-H P(C G 33100)$} & D. simulans GD18325 & A. aegypti AAEL005796 \\
\hline & D. sechellia GM23515 & A. gambiae AGAP002948 \\
\hline & D. erecta GG12377 & T. castaneum XP_970157 \\
\hline & D. yakuba GE10831 & B. mori NP_001091833 \\
\hline & D. ananassae GF 23230 & P. xuthus BAG30778 \\
\hline & D. willistoni GK11937 & A. pisum ACYPI000423 \\
\hline & D. pseudoobscura GA26519 & C. floridanus EFN65857 \\
\hline & D. persimilis GL24147 & N. vitripennis XP_003426016 \\
\hline & D. virilis $\mathrm{GJ} 14537$ & A. mellifera XP_623570 \\
\hline & D. grimshawi GH19097 & \\
\hline & D. mojavensis GI23433 & \\
\hline
\end{tabular}

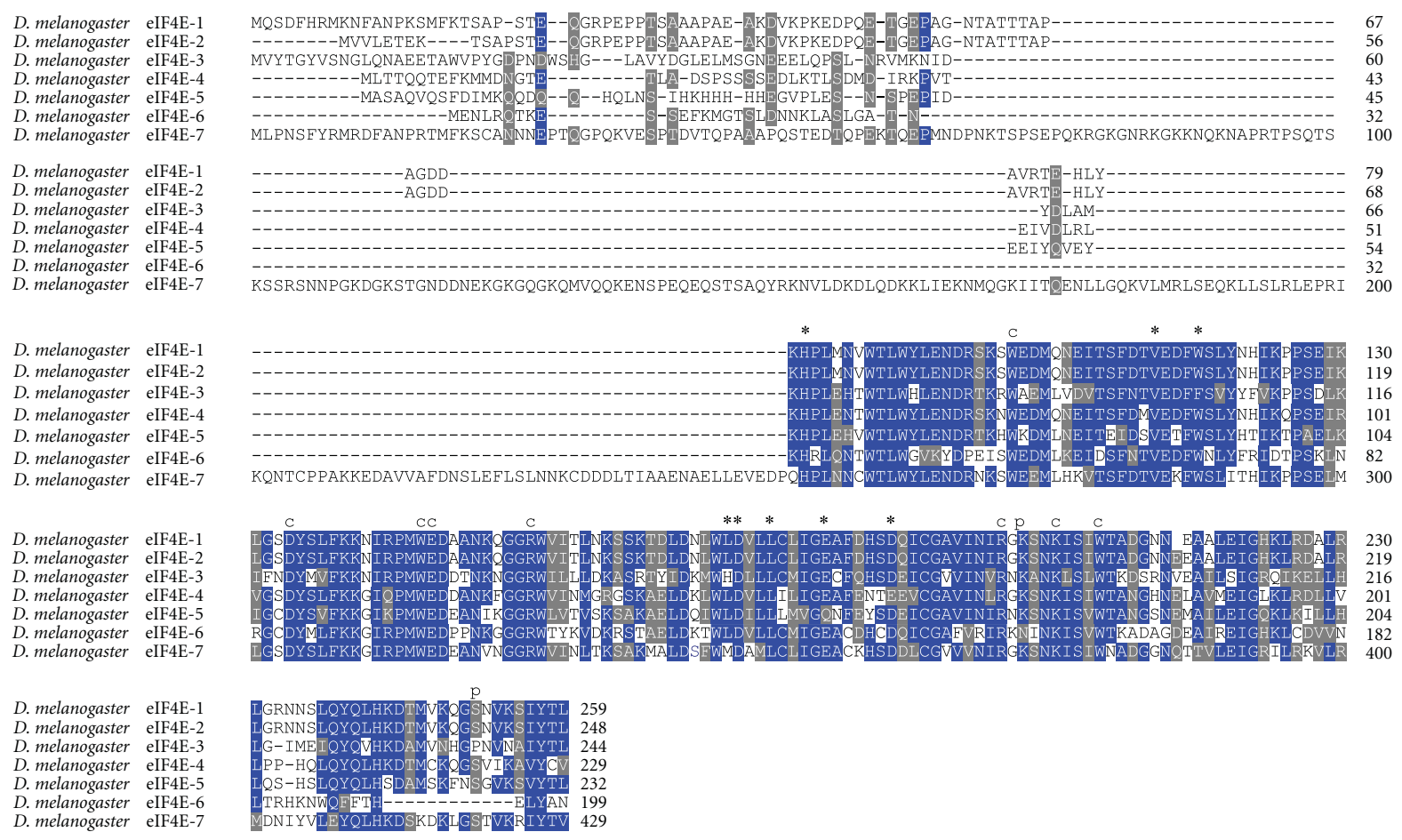

FIgure 1: Seven eIF4E cognates in D. melanogaster. (A) ClustalW alignment of amino acid sequences representing Class I eIF4E family members from D. melanogaster. An extended version of eIF4E-6, not detected in previous studies, is included. Identical (blue) or conservative (gray) amino acid residues in at least 70\% of sequences are highlighted. Conservative substitutions groups are STA, or NEQK, or NHQK, or NDEQ, or QHRK, or MILV, or MILF, or HY, or FYW, or GA. Residues essential for eIF4G- and 4E-BP binding are marked $*$; residues involved in cap binding are marked lower case $c$; phosphorylatable Ser, as well as Lys described to form a salt bridge with P-Ser, are marked lower case $p$. 


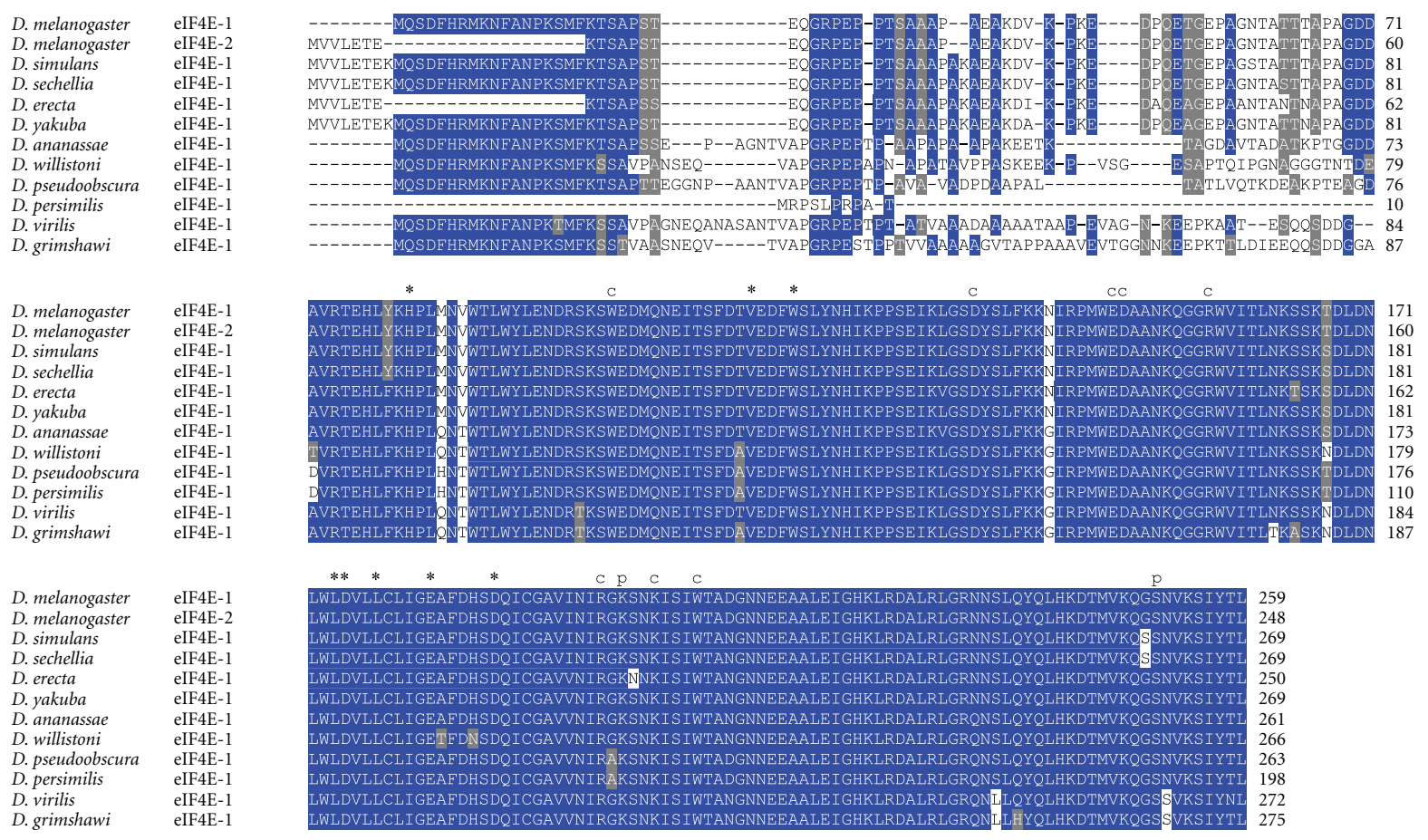

FIGURE 2: ClustalW alignment of amino acid sequences of eIF4E-1 orthologs from species of the genus Drosophila.

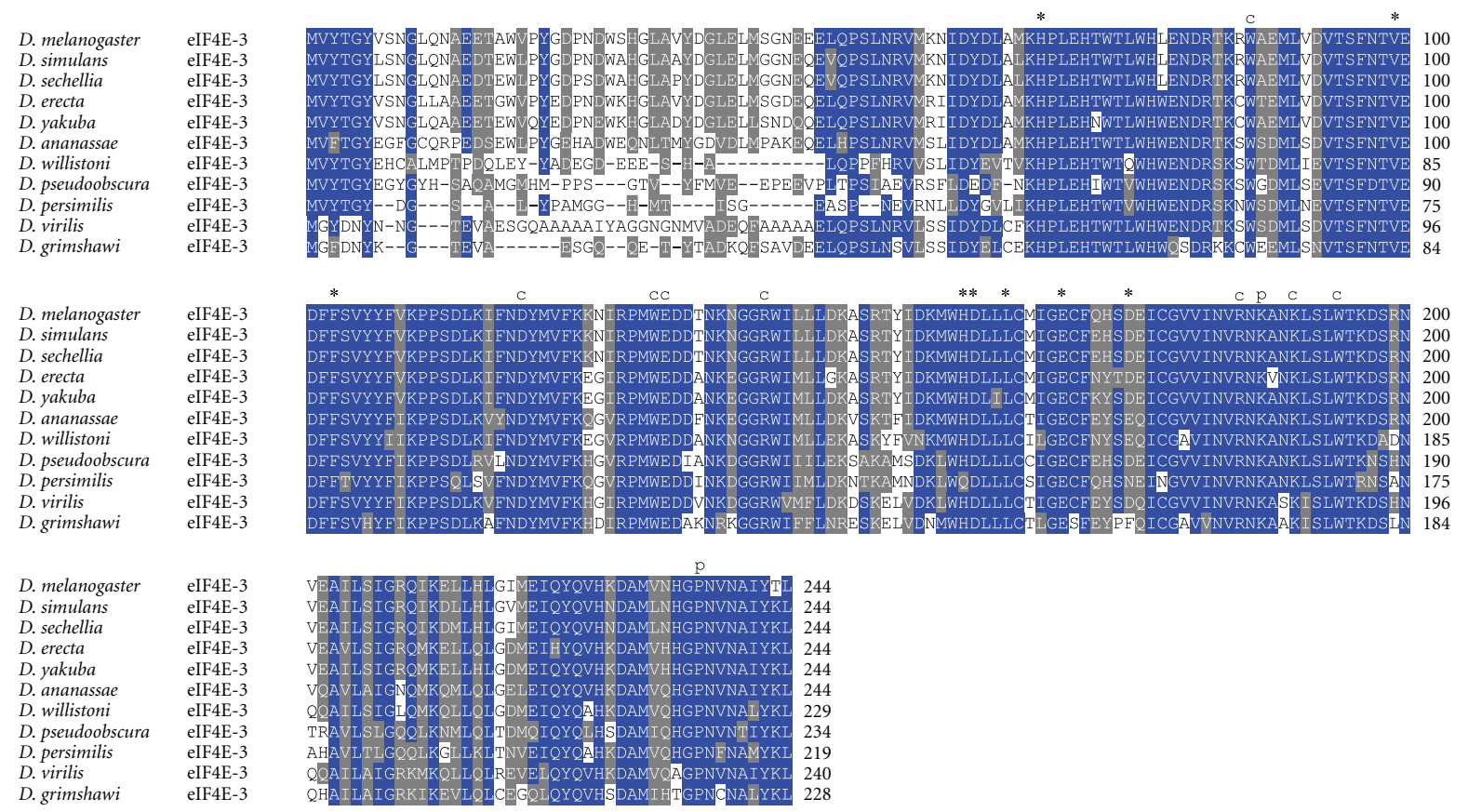

FIgURE 3: ClustalW alignment of amino acid sequences of eIF4E-3 orthologs from species of the genus Drosophila.

with seven different cognates of Class I eIF4Es (eIF4E-1 trough eIF4E-7) and one Class II gene, termed 4E-HP [25, 26]. Although sequence comparisons of all D. melanogaster eIF4Es are shown elsewhere $[25,26]$, a comparison of these proteins including an extended version of eIF4E-6 (see below) is shown in Figure 1. Using BLAST searches, it became evident that gene duplication of eIF4E also happened across the entire genus Drosophila. Overall, 61 different Class I eIF4E-family members were identified in this genus. We found that D. simulans, D. sechellia, D. erecta, and D. yakuba contain each six eIF4E genes (eIF4E-1, -3, -4, -5, -6, and $7), D$. ananassae, D. willistoni, and $D$. virilis contain each five (eIF4E-1, -3, -4, -5, and -7), D. grimshawi, D. pseudoobscura, and $D$. persimilis contain each four (eIF4E-1, -3, -4, and -5) 


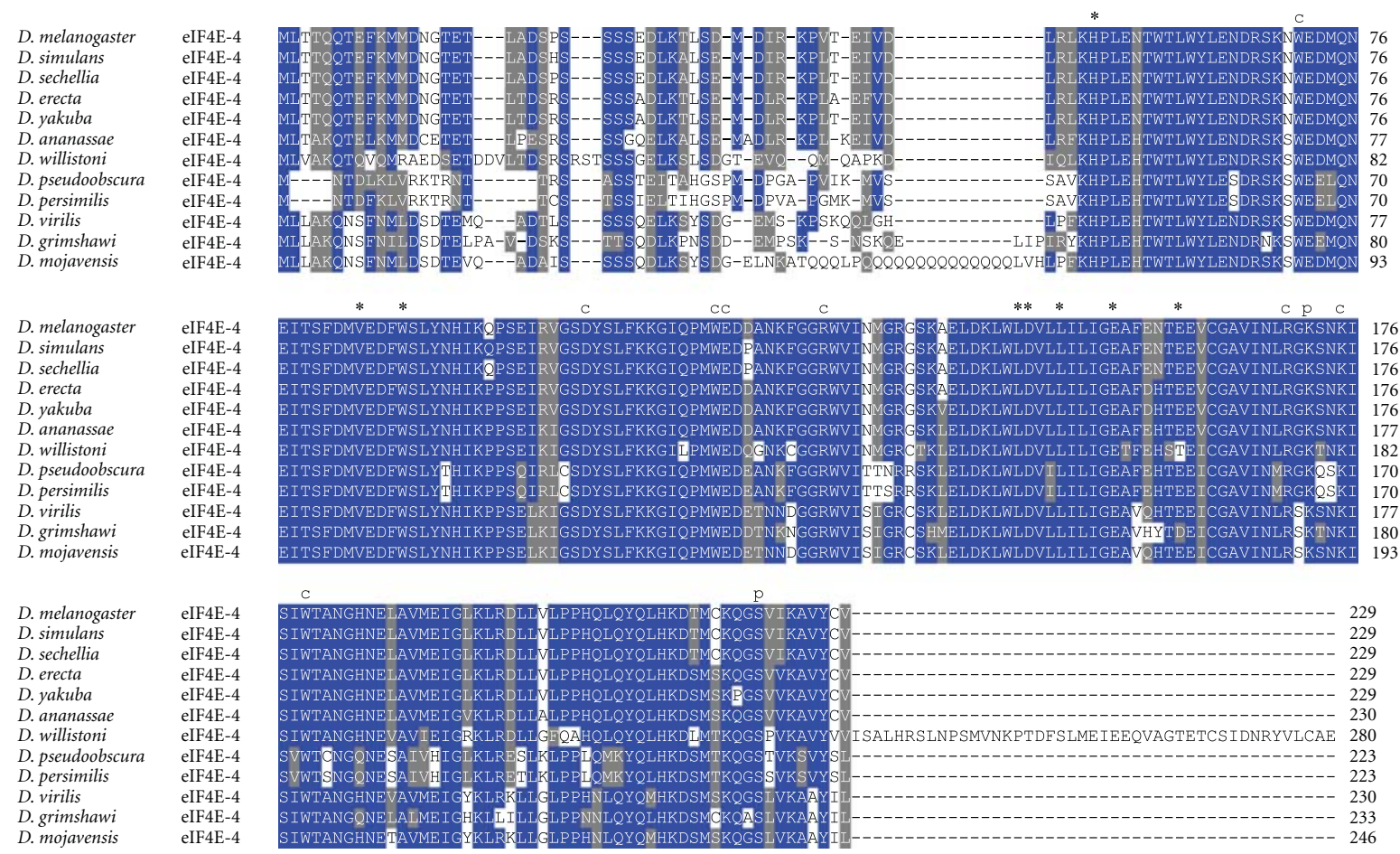

FIgURE 4: ClustalW alignment of amino acid sequences of eIF4E-4 orthologs from species of the genus Drosophila.

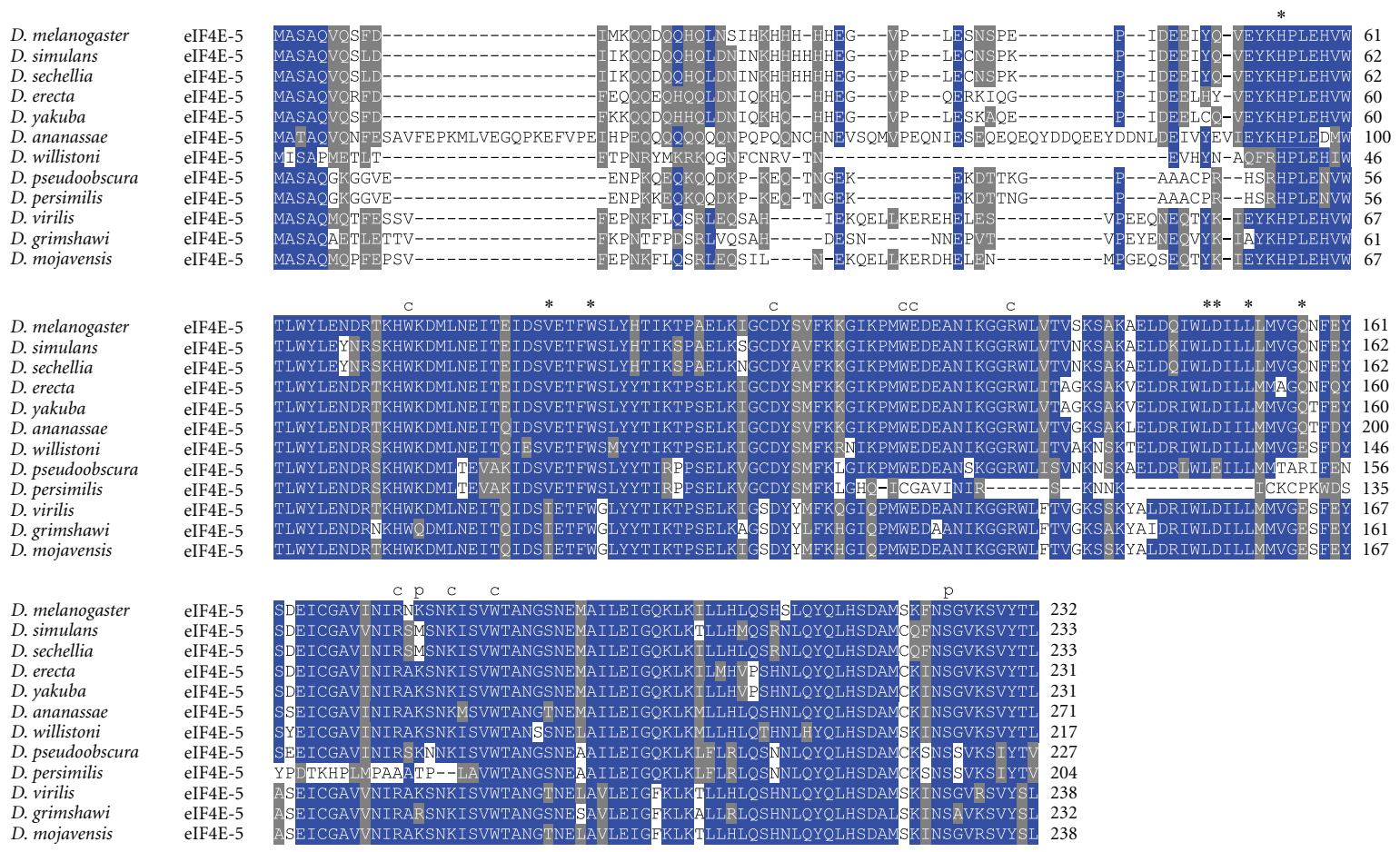

FIgURE 5: ClustalW alignment of amino acid sequences of eIF4E-5 orthologs from species of the genus Drosophila.

and D. mojavensis contains three cognates (eIF4E-4, -5, and -7) (Table 1).

It has been shown that D. melanogaster eIF4E-1 and eIF4E-2 arise by alternative splicing from the same gene (eIF4E-1/2), both proteins differing only in amino acids in the N-terminus. While eIF4E-1 contains the peptide sequence MQSDFHRMKNFANPKSMF, eIF4E-2 contains MVVLETE instead [23, 24] (Figure 1). BLAST searches showed that the gene eIF4E-1/2 exists only in $D$. melanogaster. In all other species this gene encodes only 


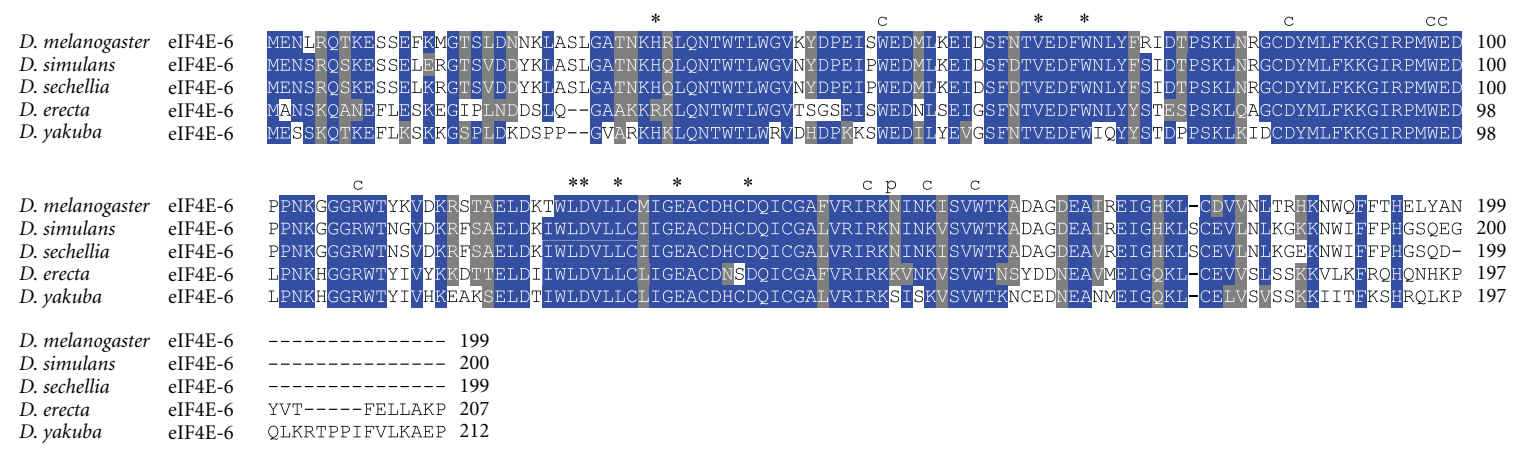

Figure 6: ClustalW alignment of amino acid sequences of eIF4E-6 orthologs from species of the genus Drosophila.

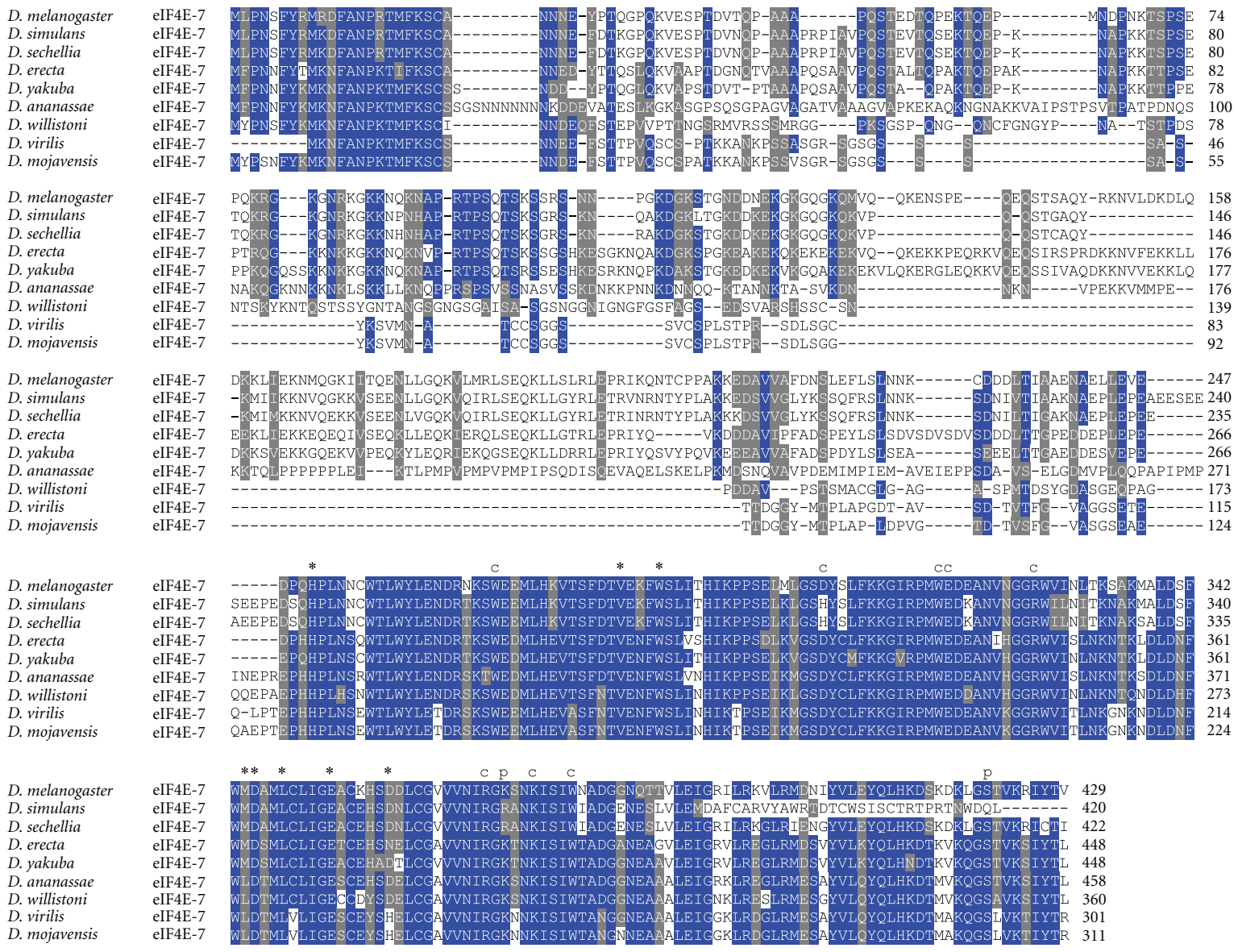

FIgURE 7: ClustalW alignment of amino acid sequences of eIF4E-7 orthologs from species of the genus Drosophila.

one protein, either eIF4E-1 (D. ananassae, D. willistoni, D. pseudoobscura, D. virilis, and D. grimshawi), eIF4E2 (D. erecta), or a protein with both N-termini fused (D. simulans, D. sechellia, and D. yakuba). Interestingly, D. persimilis encodes an eIF4E-1 with a very short and divergent N-terminus (Figure 2). The high variability in eIF4E-1 N-terminus among Drosophila species suggests that this region of the protein has no biological relevance.

All residues involved in cap- and eIF4G/4E-BP-binding as well as for phosphorylation are conserved in eIF4E-1 from across the genus Drosophila (Figure 2). In eIF4E3 , residues involved in eIF4G/4E-BP binding are mutated in two positions, namely, Trp $103>$ Phe, and Leu160 $>$ His (numbering according to D. melanogaster eIF4E-3; Figure 3 ). This significant alteration may explain the weak binding to eIF4G and 4E-BP shown in the yeast two-hybrid system [26]. Both changes are strongly conserved in eIF4E-3 across the genus Drosophila. Moreover, eIF4E-3 from all Drosophila species lack the counterpart of the phosphorylatable Ser251 of D. melanogaster eIF4E-1, possessing a proline instead [31] 


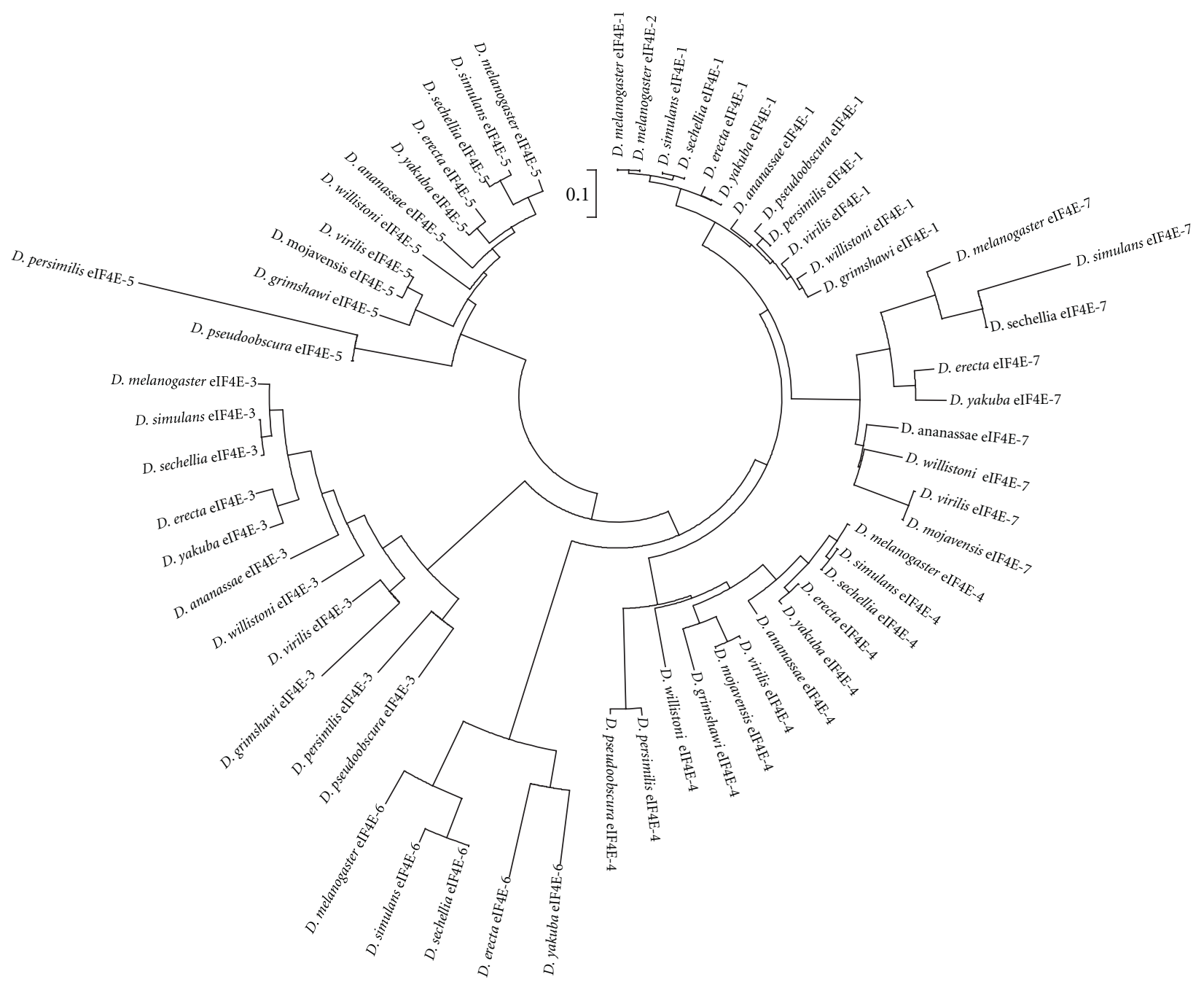

FIGURE 8: Radial phylogram computed from sequence alignments of eIF4Es from Drosophila species.

(Figure 3). D. willistoni eIF4E-4 displays the nonconservative amino acid exchange at position $160 \mathrm{Glu}>\mathrm{Thr}$ (numbering according to $D$. melanogaster eIF4E-4; Figure 4). eIF4E-5 varies considerably in length, ranging from 204 amino acids in $D$. persimilis to 271 amino acids in D. ananassae, and the N-terminus of eIF4E-5 (amino acids 1-53) is highly variable. However, eIF4E-5 is highly conserved from amino acid 54 on (Figure 5). D. persimilis eIF4E-5 also diverges from its orthologs in at least ten functionally important amino acids (Figure 5).

Recent experimental evidence supports an extended Cterminus of eIF4E-6 (Tettweiler, Hernández, Sonenberg, and Lasko, unpublished), not detected in previous studies $[25,26]$. This extended eIF4E-6 showed the highest similarity to eIF4E-3 and has functionally important residues diverged from eIF4E-1 (Figure 1). One of the differences is a lack of phosphorylatable Ser251 (numbering of eIF4E1). Surprisingly, although extended eIF4E-6 possesses all amino acids involved in eIF4G/4E-BP binding, experimental evidence showed that it does not bind either of them (Tettweiler, Hernández, Sonenberg, and Lasko, unpublished).
The extended eIF4E- 6 could only be detected in five species, all of which contain conserved residues important for cap binding (Figure 6). In D. erecta, a conserved substitution His $>$ Arg is observed in position 33 (numbering according to D. melanogaster eIF4E-6; Figure 6), a residue essential for eIF4G/4E-BP binding. Similar to eIF4E-3, no eIF4E-6 from any species has the counterpart of eIF4E-1 Ser251 (Figure 6).

eIF4E-7 is the longest protein from Class I family members with 301 amino acids in $D$. virilis to 458 amino acids in D. ananassae (Figure 7). The high degree of discrepancy in length is attributed to the variability in the $\mathrm{N}$ terminal moiety of the protein (Figure 7). Although eIF4E7 orthologs are most similar to eIF4E-1, eIF4E-7 from all Drosophila species cluster together in separate phylogram branches (Figure 8). Several species are lacking functionally important residues in the eIF4E-7 C-terminus. In particular, in D. simulans eIF4E-7 the eIF4E-1 Ser251 counterpart is substituted by a Gln, albeit it is conserved in other Drosophila species (Figure 7).

Overall, our analyses indicate that the seven eIF4Ecognates in the genus Drosophila form discrete clusters 


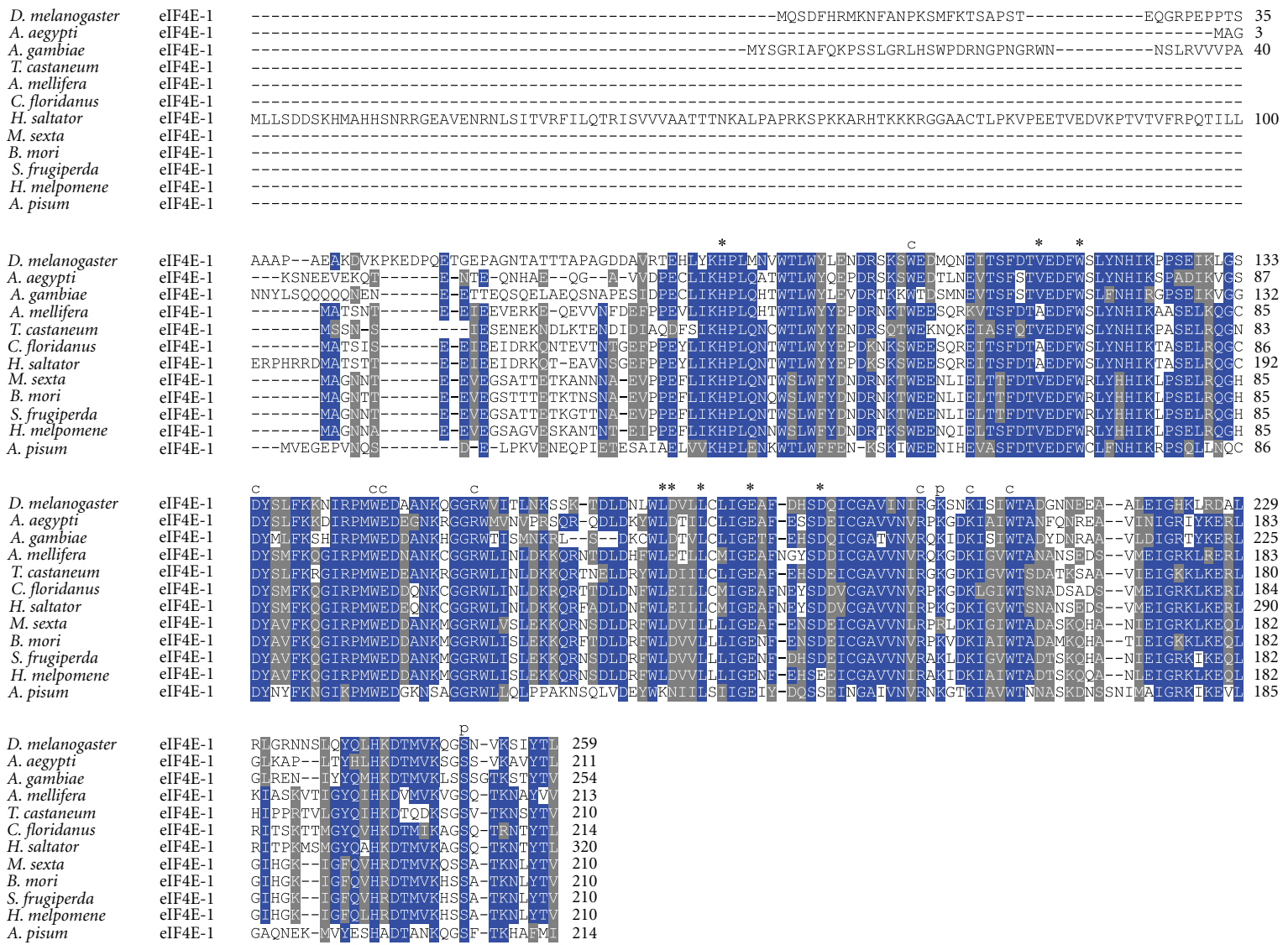

FIGURE 9: Orthologs of D. melanogaster eIF4E-1 in other insects. ClustalW alignment of amino acid sequences of eIF4E-1 orthologs from diverse insect species.

(Figure 8), indicating that they evolved separately from each other before the radiation of ancestral Drosophila into the current species.

3.2. eIF4E Proteins in Other Insects. We analyzed protein annotations from all insect genomes that are publicly available. These include species representing non-Drosophila Diptera, as well as Hymenoptera, Coleoptera, Lepidoptera, and Hemiptera. Outside of the genus Drosophila, eleven more Class I eIF4Es were identified in different insect species (Figures 9 and 10). In contrast to Drosophila species, which contain three to seven different Class I eIF4Es cognates, we identified only a single Class I eIF4E gene in each insect genome analyzed, all of them related to $D$. melanogaster eIF4E-1 and with a highly variable $\mathrm{N}$-terminus moiety (Figure 9). All amino acids described to be involved in cap and eIF4G/4E-BP binding are conserved in all insect eIF4Es analyzed. The exception is Leu174 (numbering according to D. melanogaster eIF4E-1), which is exchanged to Lys in A. pisum eIF4E-1.

Several evolutionary forces could account for the multiplicity of eIF4E genes in Drosophila genus, as opposed to the other insect lineages containing only one eIF4E gene. Diptera experienced three episodes of explosive radiation, one of them happened during the emergence of Schizophora (close relatives of $D$. melanogaster) in the early Tertiary Period (65 MYA). The Schizophora radiation originated most of the family-level diversity in Diptera, accounting for more than a third of extant fly diversity [2, 51-53]. Interestingly, the temporal pattern of fruit flies speciation corresponds with the major periods of climate cooling and habitat fragmentation during the Cenozoic Era, which could be one of the causes for stimulating the rapid fruit flies speciation [52]. The vigorous burst of diversification of the Schizophora was also coincident with the emergence of some developmental novelties, including the ptilinal sac, an improved escape mechanism for the fly from its puparium [53]. Since flies originated in wet environments, it has been suggested that the emergence of an impervious pupation to their surrounding allowed flies to adapt to almost all substrates and to occupy a broad range of trophic niches [53]. The explosive diversification of schizophoran could have induced the repeated events of eIF4E duplication in Drosophila species. It is conceivable that specific modes of temporal and spatial regulation of protein synthesis driven by different eIF4E isoforms conferred an adaptive advantage to these environmental changes.

At the molecular level, genomic studies revealed that repeated tandem gene duplication has generated $\sim 80 \%$ of the nascent genes during the D. melanogaster subgroup 


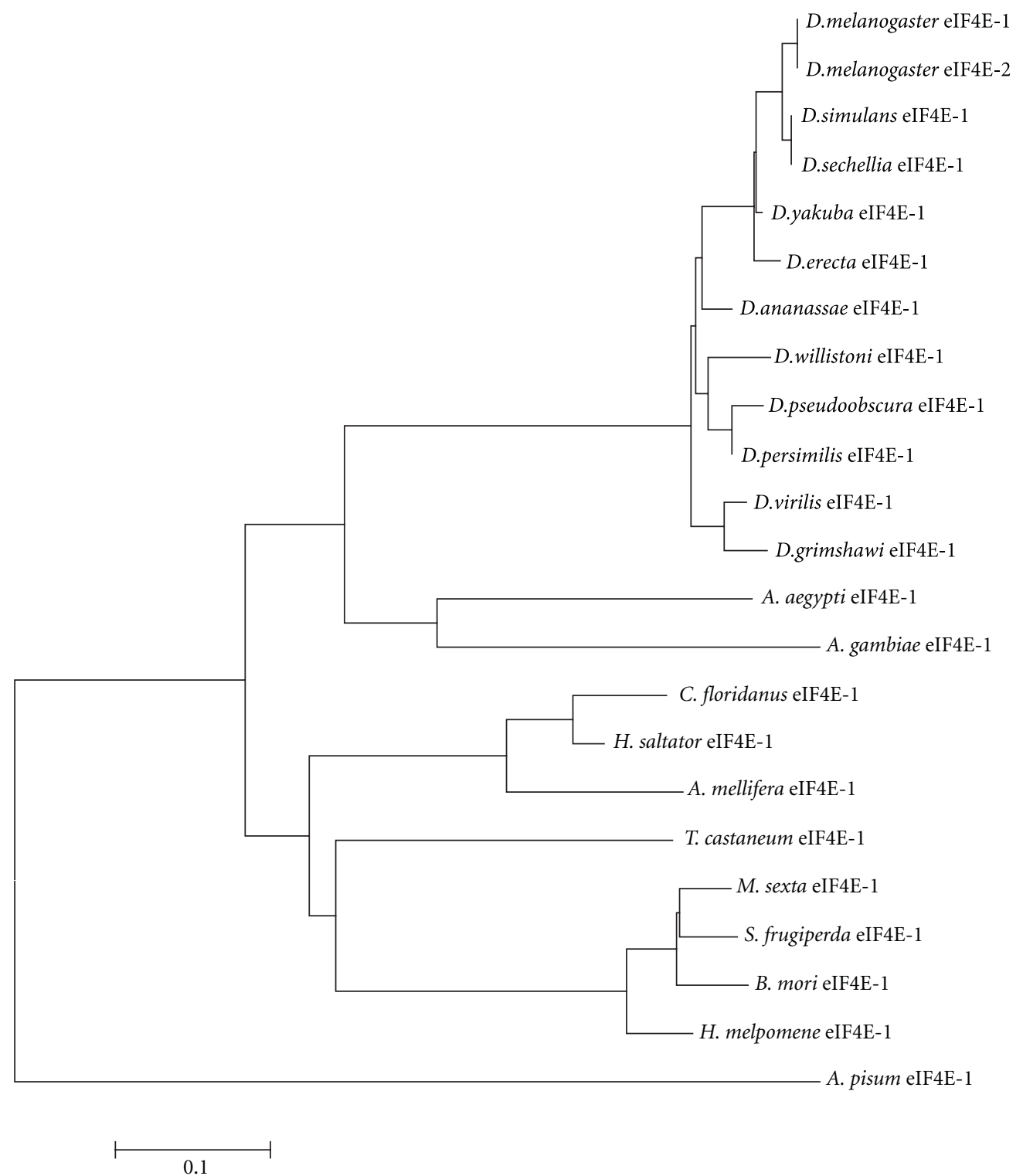

Figure 10: Phylogram computed from sequence alignments of eIF4E-1 from diverse insect species.

evolution, and that retroposition has generated $\sim 10 \%$ of the new genes in these species $[54,55]$. Five to eleven new functional genes per million years were originated during evolution of this lineage $[54,55]$. These findings may explain that D. melanogaster eIF4E-1/2, eIF4E-3, eIF4E-4, and eIF4E5 genes lie within a narrow region of the chromosome $3 \mathrm{~L}$ and share exon/intron genomic structure [23, 24, 26]. Thus, it is conceivable that these genes originated by tandem duplication of an original eIF4E-1 gene. On the other hand, eIF4E-6 and eIF4E-7 genes, which lie in different chromosomes and contain no introns in the core region of the genes [26], could have originated by retroposition events from eIF4E-3 and eIF4E-1, respectively. Noteworthy, $D$. mojavensis only encodes eIF4E- $4,-5$, and -7 , but not eIF4E1. Since eIF4E-7 appears to be an extended eIF4E-1, we speculate that eIF4E-7 functions for eIF4E-1 in this species, which at a certain point of evolution lost the original eIF4E1 gene. When available in the near future, the chromosomic location of D. mojavensis eIF4E-7 gene could corroborate this hypothesis.

3.3. 4E-HP in the Genus Drosophila. We also analyzed Class II eIF4E, namely, 4E-HP, in species of the genus Drosophila. In a striking contrast to all eIF4Es, a single copy of the $4 E-H P$ gene was identified in each Drosophila species. Interestingly, $4 \mathrm{E}-\mathrm{HP}$ displays an unusually strong conservation in the $\mathrm{N}$-terminal moiety of the protein and residues important for eIF4G/4E-BP binding diverge considerably from eIF4E1 in all Drosophila species (Figure 11). This is the case of Asn46, Gln82, Glu139, Asn140, and Met143 (positions refer to D. melanogaster 4E-HP), which are His, Glu, Leu, 


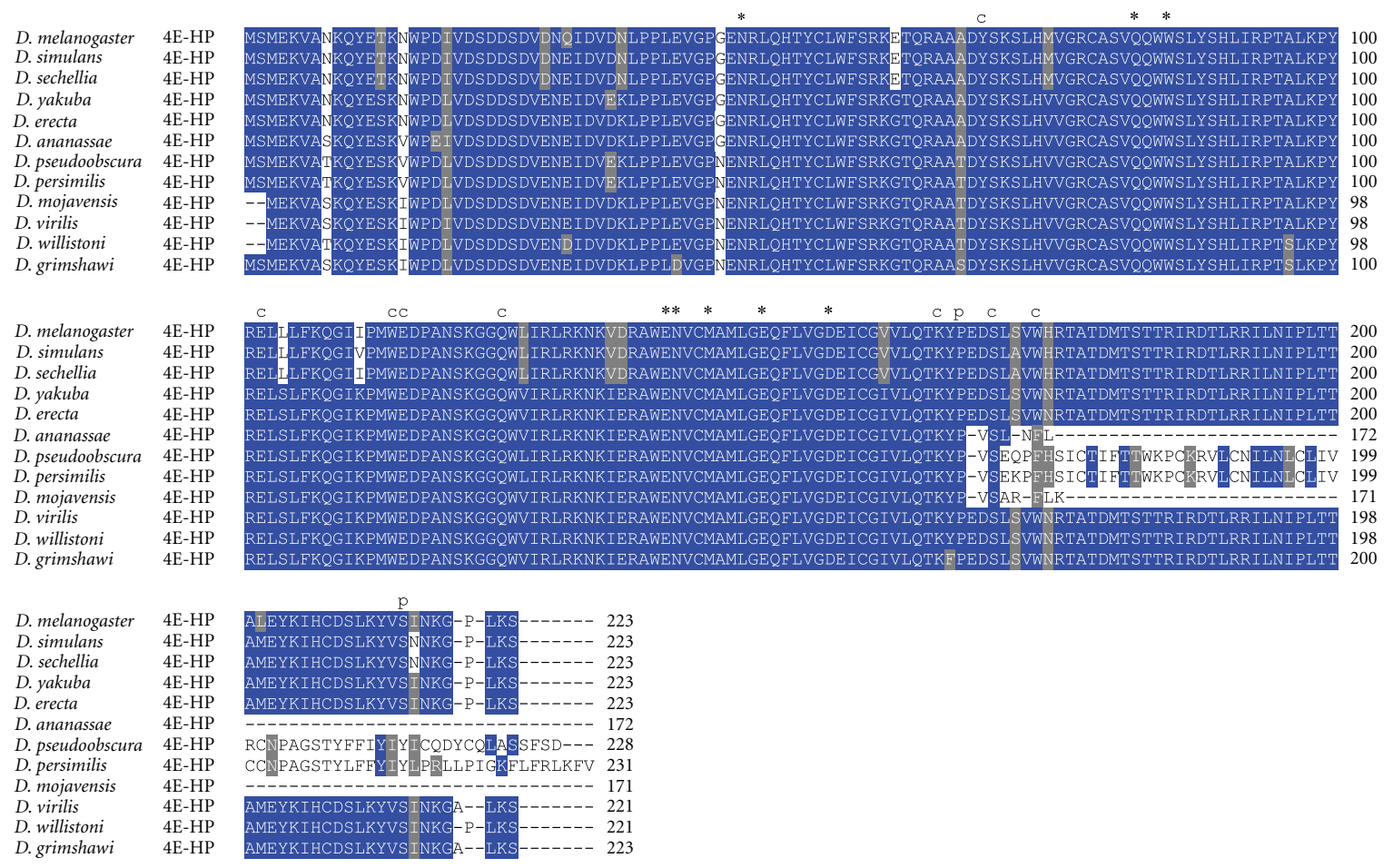

FIGURE 11: ClustalW alignment of amino acid sequences of 4E-HP orthologs from species of the genus Drosophila.

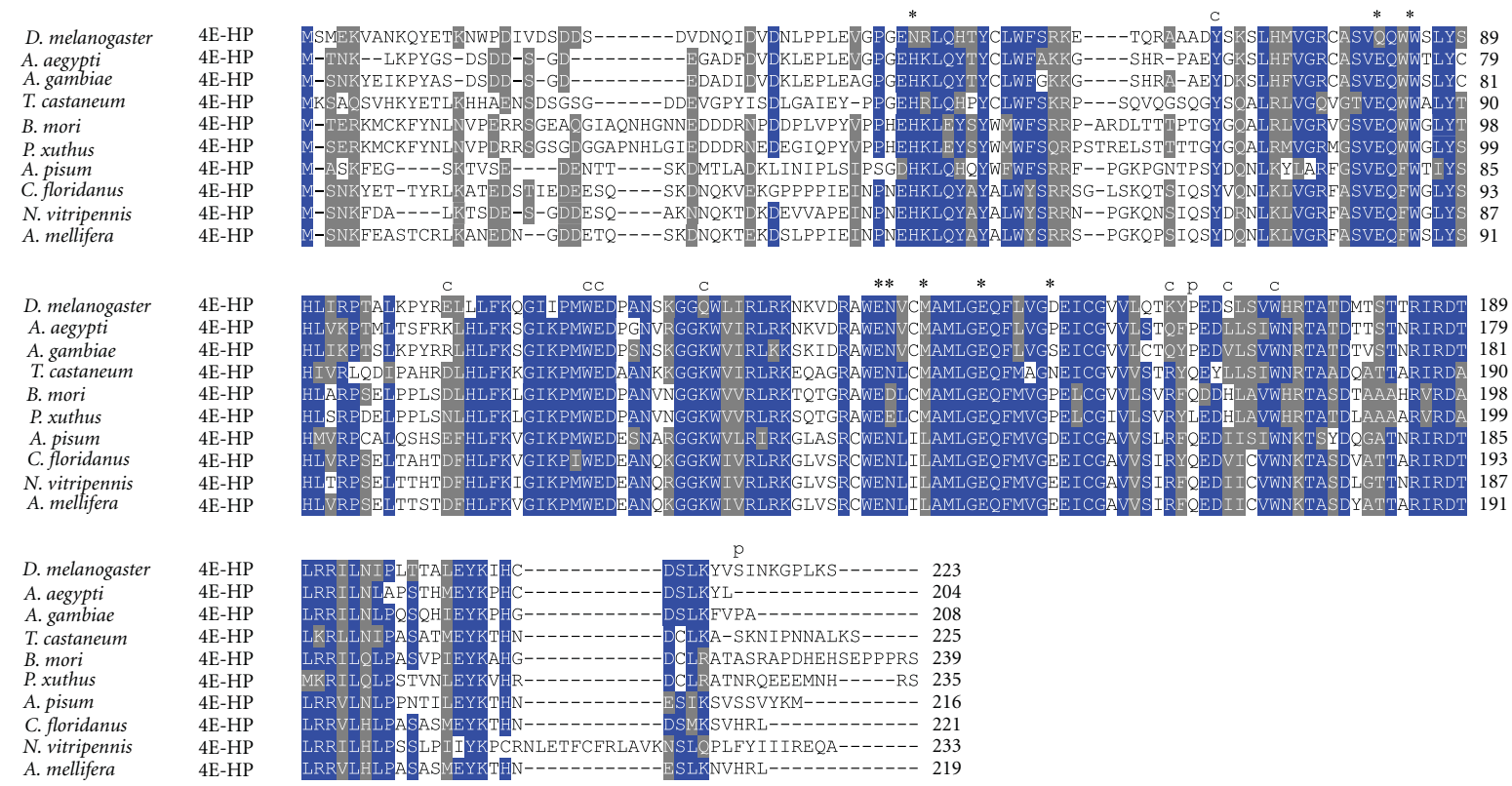

FIGURE 12: Orthologs of D. melanogaster 4E-HP in diverse insect species. ClustalW alignment of amino acid sequences of $4 \mathrm{E}-\mathrm{HP}$ orthologs from diverse insect species.

Asp, and Leu residues in most D. melanogaster eIF4Es, respectively. Accordingly, D. melanogaster 4E-HP does not bind eIF4G [26] but it interacts with Bicoid (bcd) and Brain Tumor (Brat) instead [27, 33]. Many residues critical for cap binding underwent both conservative and nonconservative mutations in 4E-HP from all Drosophila species analyzed. Thus, Tyr68, Glu102, Gln124, Lys164, Pro166, and Ser169 are Trp, Asp, Arg, Arg, Lys, and Lys in all D. melanogaster eIF4Es, respectively. The counterpart of phosphorylatable Ser251 in $D$. melanogaster eIF4E-1 is conserved in most species of the genus Drosophila. Finally, D. ananassae and D. mojavensis $4 \mathrm{E}-\mathrm{HP}$ is considerably shorter than $4 \mathrm{E}-\mathrm{HP}$ in other species (Figure 11).

3.4. 4E-HP in Other Insects. Further BLAST searches identified again single-copy $4 E-H P$ genes in other insect species. 


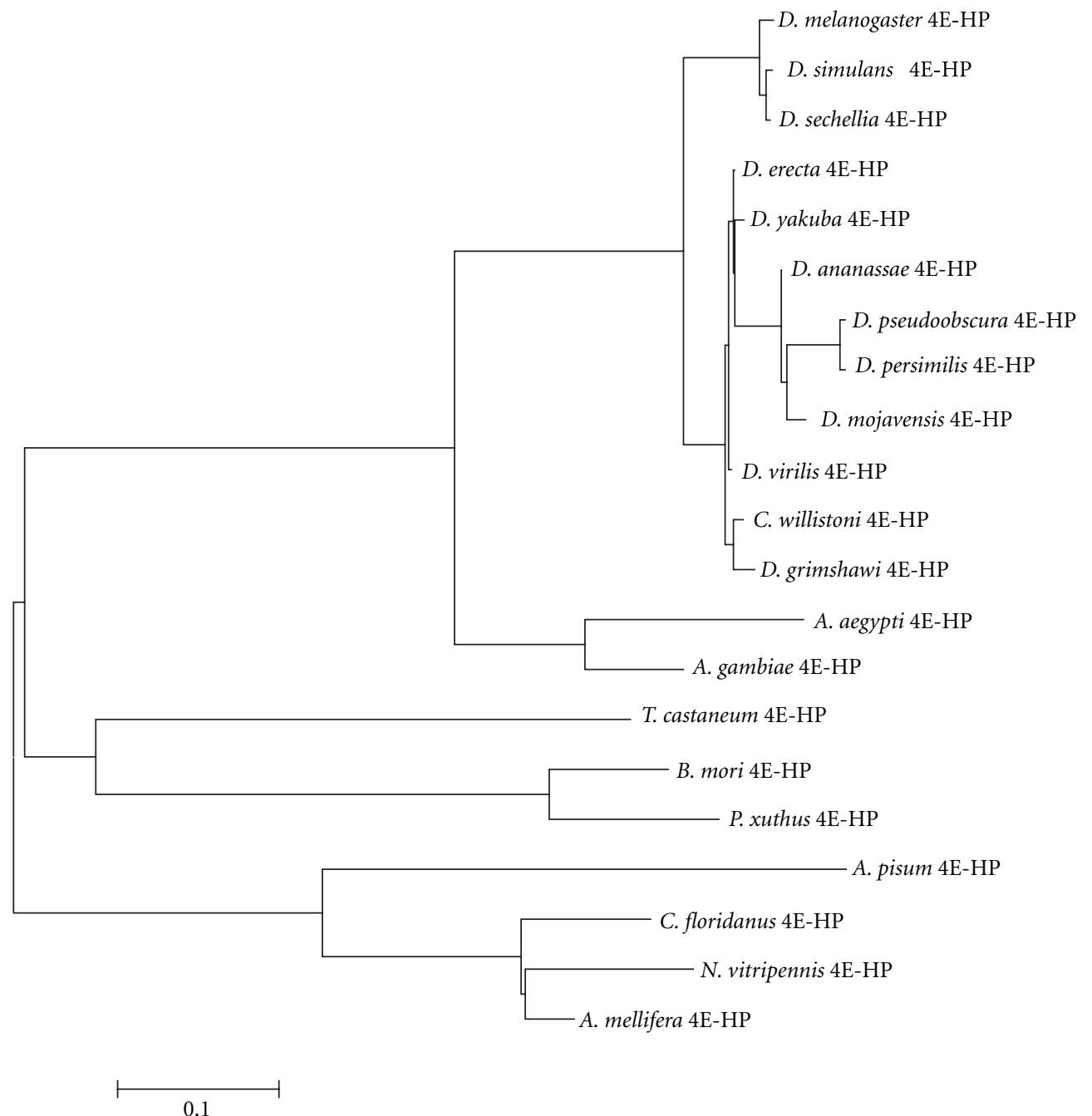

Figure 13: Phylogram computed from sequence alignments of 4E-HP from diverse insect species.

Sequence comparison showed a strong conservation in the core region of the protein, albeit $\mathrm{N}$ - and $\mathrm{C}$-terminus are less conserved (Figure 12). In contrast to 4E-HP from Drosophila species, all residues important for eIF4G/4E-BP binding in eIF4Es are conserved in 4E-HP from all analyzed insects outside the genus Drosophila. This might suggest that $4 \mathrm{E}-$ HP in non-Drosophila insects do bind eIF4G/4E-BP. Similar to 4E-HP from all Drosophila species, most residues critical for cap-binding also show conservative changes in $4 \mathrm{E}-\mathrm{HP}$ from Insecta species. The counterpart of phosphorylatable Ser251 of eIF4E-1 is only conserved in 4E-HP from $D$. melanogaster, T. castaneum, and A. pisum (Figure 12). A phylogram showing the relationships among 4E-HPs from all insects analyzed is shown in Figure 13.

Phylograms construction including all Drosophila 4E$\mathrm{HP}$ and eIF4E sequences showed that all 4E-HPs cluster separately from all eIF4Es (not shown). Moreover, 4E-HP is widespread across metazoa, plants, and some fungi [45], and the D. melanogaster and human $4 \mathrm{E}-\mathrm{HP}$ are able to bind the $5^{\prime}$ cap structure of the mRNA but not eIF4G $[26,56]$, thereby acting as a translational repressor of mRNAs associated to 4E-HP $[27,33,34]$. This, together with the findings that the A. thaliana [57] (termed nCBP) and the C. elegans [58] (termed IFE-4) orthologs can compete with reticulocyte eIF4E to reduce $\mathrm{m}^{7} \mathrm{GTP}$ binding and can be found associated with small ribosomal subunits, respectively, which is consistent with a regulatory function, led to the suggestion that 4E-HP diverged from a widespread ancestral Class I eIF4E into a translational repressor in mammals and in Drosophila [59]. This is supported by the observation that all residues important for eIF4G/4E-BP binding in eIF4Es are highly conserved in 4E-HP from non-Drosophila insects, but not in Drosophila species (Figure 12). Thus, 4E-HP from insects outside the genus Drosophila should bind eIF4G and promote translation. It is important to experimentally analyze this controversial hypothesis.

3.5. Class III eIF4Es. Among insects, only two partial Class III eIF4Es were identified, one in A. mellifera and one in $H$. coagulata. Both are missing the start methionine and were therefore not further analyzed. 


\section{Concluding Remarks}

Constant updating of genomic data and annotations as well as improved search algorithms provided a more comprehensive overview of insect eIF4E cognates than previously possible. Here we presented an updated analysis of eIF4Es and 4E-HP across Insecta. This analysis revealed an interesting observation, that is, that eIF4E is a single-copy gene in all insects analyzed, but in the genus Drosophila this gene underwent a striking multiplication along with the explosive radiation this lineage went through in the early Tertiary. eIF4E diversification led to variability of biochemical properties and physiological specialization, as documented for some $D$. melanogaster eIF4Es. It would be worthy to investigate whether this is also the case for other species with several eIF4E cognates, as sequence alignments showed how diverse this protein is in the genus Drosophila. It also would be interesting to search for novel, so far unknown, 4E-BPs in other Drosophila species. Moreover, it is possible that different eIF4Es could translate specific target mRNAs.

eIF4E from more insect species must be analyzed to obtain a better picture of the evolution and diversity of eIF4E in this group, and to see whether the rise of multiple eIF4E genes is found in other insect lineages too. If so, correlating eIF4E evolution with the natural history of those lineages might lead us to find general, underlying forces driving the translation apparatus evolution.

\section{Acknowledgments}

G. Hernández is supported by the National Institute for Cancer (Instituto Nacional de Cancerología, México). G. Tettweiler, P. Lasko, and N. Sonenberg were supported by a grant to P. Lasko and N. Sonenberg from the Canadian Institute of Health Research.

\section{References}

[1] P. J. Mayhew, "Why are there so many insect species? Perspectives from fossils and phylogenies," Biological Reviews, vol. 82, no. 3, pp. 425-454, 2007.

[2] D. A. Grimaldi and M. S. Engel, Evolution of the Insects, Cambridge University Press, New York, NY, USA, 2005.

[3] F. A. Bisby, Y. R. Roskov, T. M. Orrell, D. Nicolson, and L. E. Paglinawan, "Catalogue of life: 2010 annual checklist," Species 2000, vol. 23, no. 24, pp. 33-54, 2010.

[4] C. Mora, D. P. Titterson, S. Adl, A. G. B. Simpson, and B. Worm, "How many species are there on Earth and in the ocean," PLoS Biology, vol. 9, no. 8, Article ID e100112, 2011.

[5] M. S. Engel and D. A. Grimaldi, "New light shed on the oldest insect," Nature, vol. 427, no. 6975, pp. 627-630, 2004.

[6] M. W. Gaunt and M. A. Miles, "An insect molecular clock dates the origin of the insects and accords with palaeontological and biogeographic landmarks," Molecular Biology and Evolution, vol. 19, no. 5, pp. 748-761, 2002.

[7] J. B. Whitfield and K. M. Kjer, "Ancient rapid radiations of insects: challenges for phylogenetic analysis," Annual Review of Entomology, vol. 53, pp. 449-472, 2008.

[8] E. A. Jarzembowski and A. J. Ross, "Insect origination and extinction in the Phanerozoic," in Biotic Recovery from Mass
Extinction Events, M. B. Hart, Ed., pp. 65-78, Geological Society Special Publication, London, UK, 1996.

[9] P. G. Kevan, W. G. Chaloner, and D. B. O. Savile, "Interrelationships of early terrestrial arthropods and plants," Paleontology, vol. 18, pp. 391-417, 1975.

[10] N. Sonenberg and A. G. Hinnebusch, "Regulation of Translation Initiation in Eukaryotes: mechanisms and Biological Targets," Cell, vol. 136, no. 4, pp. 731-745, 2009.

[11] R. J. Jackson, C. U. T. Hellen, and T. V. Pestova, "The mechanism of eukaryotic translation initiation and principles of its regulation," Nature Reviews Molecular Cell Biology, vol. 11, no. 2, pp. 113-127, 2010.

[12] J. Marcotrigiano, A. C. Gingras, N. Sonenberg, and S. K. Burley, "Cocrystal structure of the messenger RNA 5' capbinding protein (elF4E) bound to 7-methyl-GDP," Cell, vol. 89, no. 6, pp. 951-961, 1997.

[13] H. Matsuo, H. Li, A. M. McGuire et al., "Structure of translation factor elF4E bound to m7GDP and interaction with $4 \mathrm{E}$ binding protein," Nature Structural Biology, vol. 4, no. 9, pp. 717-724, 1997.

[14] K. Tomoo, X. Shen, K. Okabe et al., "Crystal structures of 7-methylguanosine $5^{\prime}$-triphosphate (m7GTP)- and P1-7methylguanosine-P3-adenosine-5', 5'-triphosphate (m7GpppA)-bound human full-length eukaryotic initiation factor 4E: biological importance of the C-terminal flexible region," Biochemical Journal, vol. 362, no. 3, pp. 539-544, 2002.

[15] K. Tomoo, X. Shen, K. Okabe et al., "Structural features of human initiation factor $4 \mathrm{E}$, studied by X-ray crystal analyses and molecular dynamics simulations," Journal of Molecular Biology, vol. 328, no. 2, pp. 365-383, 2003.

[16] J. D. Richter and N. Sonenberg, "Regulation of cap-dependent translation by eIF4E inhibitory proteins," Nature, vol. 433, no. 7025, pp. 477-480, 2005.

[17] N. Sonenberg and A. G. Hinnebusch, "New modes of translational control in development, behavior, and disease," Molecular Cell, vol. 28, no. 5, pp. 721-729, 2007.

[18] L. Furic, L. Rong, O. Larsson et al., "EIF4E phosphorylation promotes tumorigenesis and is associated with prostate cancer progression," Proceedings of the National Academy of Sciences of the United States of America, vol. 107, no. 32, pp. 14134-14139, 2010.

[19] P. E. D. Lachance, M. Miron, B. Raught, N. Sonenberg, and P. Lasko, "Phosphorylation of eukaryotic translation initiation factor 4E is critical for growth," Molecular and Cellular Biology, vol. 22, no. 6, pp. 1656-1663, 2002.

[20] G. Ross, J. R. Dyer, V. F. Castellucci, and W. S. Sossin, "Mnk is a negative regulator of cap-dependent translation in Aplysia neurons," Journal of Neurochemistry, vol. 97, no. 1, pp. 79-91, 2006.

[21] F. G. Maroto and J. M. Sierra, "Purification and characterization of mRNA cap-binding protein from Drosophila melanogaster embryos," Molecular and Cellular Biology, vol. 9, no. 5, pp. 2181-2190, 1989.

[22] G. Hernández and J. M. Sierra, "Translation initiation factor eIF-4E from Drosophila: cDNA sequence and expression of the gene," Biochimica et Biophysica Acta, vol. 1261, no. 3, pp. 427431, 1995.

[23] G. Hernández, R. Diez Del Corral, J. Santoyo, S. Campuzano, and J. M. Sierra, "Localization, structure and expression of the gene for translation initiation factor eIF-4E from Drosophila melanogaster," Molecular and General Genetics, vol. 253, no. 5, pp. 624-633, 1997.

[24] C. A. Lavoie, P. E. D. Lachance, N. Sonenberg, and P. Lasko, "Alternatively spliced transcripts from the Drosophila eIF4E 
gene produce two different cap-binding proteins," The Journal of Biological Chemistry, vol. 271, no. 27, pp. 16393-16398, 1996.

[25] P. Lasko, "The Drosophila melanogaster genome: translation factors and RNA binding proteins," Journal of Cell Biology, vol. 150, no. 2, pp. F51-F56, 2000.

[26] G. Hernández, M. Altmann, J. M. Sierra et al., "Functional analysis of seven genes encoding eight translation initiation factor 4E (eIF4E) isoforms in Drosophila," Mechanisms of Development, vol. 122, no. 4, pp. 529-543, 2005.

[27] P. F. Cho, F. Poulin, Y. A. Cho-Park et al., "A new paradigm for translational control: inhibition via $5^{\prime}-3^{\prime}$ mRNA tethering by Bicoid and the eIF4E cognate 4EHP," Cell, vol. 121, no. 3, pp. 411-423, 2005.

[28] G. Hernández, P. Vázquez-Pianzola, J. M. Sierra, and R. Rivera-Pomar, "Internal ribosome entry site drives capindependent translation of reaper and heat shock protein 70 mRNAs in Drosophila embryos," RNA, vol. 10, no. 11, pp. 1783-1797, 2004.

[29] H. McNeill, G. M. Craig, and J. M. Bateman, "Regulation of neurogenesis and epidermal growth factor receptor signaling by the insulin receptor/target of rapamycin pathway in Drosophila," Genetics, vol. 179, no. 2, pp. 843-853, 2008.

[30] L. Gong, M. Puri, M. Ünlü et al., "Drosophila ventral furrow morphogenesis: a proteomic analysis," Development, vol. 131, no. 3, pp. 643-656, 2004.

[31] G. Hernández, H. Han, V. Gandin, T. Ferreira, N. Sonenberg, and P. Lasko, "Drosophila eukaryotic initiation factor 4E3 is essential in post-meiotic stages of spermatogenesis," Development, In press.

[32] S. M. Gorski, S. Chittaranjan, E. D. Pleasance et al., "A SAGE approach to discovery of genes involved in autophagic cell death," Current Biology, vol. 13, no. 4, pp. 358-363, 2003.

[33] P. F. Cho, C. Gamberi, Y. Cho-Park, I. B. Cho-Park, P. Lasko, and N. Sonenberg, "Cap-dependent translational inhibition establishes two opposing morphogen gradients in Drosophila embryos," Current Biology, vol. 16, no. 20, pp. 2035-2041, 2006.

[34] J. C. Villaescusa, C. Buratti, D. Penkov et al., "Cytoplasmic Prep1 interacts with 4EHP inhibiting Hoxb4 translation," PLoS ONE, vol. 4, no. 4, Article ID e5213, 2009.

[35] K. P. Menon, S. Sanyal, Y. Habara et al., "The translational repressor Pumilio regulates presynaptic morphology and controls postsynaptic accumulation of translation factor eIF4E," Neuron, vol. 44, no. 4, pp. 663-676, 2004.

[36] S. J. Sigrist, P. R. Thiel, D. F. Reiff, P. E. D. Lachance, P. Lasko, and C. M. Schuster, "Postsynaptic translation affects the efficacy and morphology of neuromuscular junctions," Nature, vol. 405, no. 6790, pp. 1062-1065, 2000.

[37] P. L. Graham, J. L. Yanowitz, J. K. M. Penn, G. Deshpande, and P. Schedl, "The translation initiation factor eif4e regulates the Sex-Specific expression of the master switch gene Sxl in Drosophila melanogaster," PLoS Genetics, vol. 7, no. 7, Article ID e1002185, 2011.

[38] M. Miron, J. Verdú, P. E. D. Lachance, M. J. Birnbaum, P. F. Lasko, and N. Sonenberg, "The translational inhibitor 4E$\mathrm{BP}$ is an effector of $\mathrm{PI}(3) \mathrm{K} / \mathrm{Akt}$ signalling and cell growth in Drosophila," Nature Cell Biology, vol. 3, no. 6, pp. 596-601, 2001.

[39] F. Piccioni, V. Zappavigna, and A. C. Verrotti, "A cup full of functions," RNA Biology, vol. 2, no. 4, pp. 125-128, 2005.

[40] S. K. Lee, J. S. Lee, K. S. Shin, and S. J. Yoo, "Translation initiation factor $4 \mathrm{E}$ (eIF4E) is regulated by cell death inhibitor, Diap 1," Molecules and Cells, vol. 24, no. 3, pp. 445-451, 2007.
[41] S. Iwasaki, T. Kawamata, and Y. Tomari, "Drosophila argonaute1 and argonaute2 employ distinct mechanisms for translational repression," Molecular Cell, vol. 34, no. 1, pp. 5867, 2009.

[42] A. Yarunin, R. E. Harris, M. P. Ashe, and H. L. Ashe, "Patterning of the Drosophila oocyte by a sequential translation repression program involving the $\mathrm{d} 4 \mathrm{EHP}$ and Belle translational repressors," RNA Biology, vol. 8, no. 5, pp. 904-912, 2011.

[43] A. G. Clark, M. B. Eisen, D. R. Smith et al., "Evolution of genes and genomes on the Drosophila phylogeny," Nature, vol. 450, no. 7167, pp. 203-218, 2007.

[44] A. Papanicolaou, S. Gebauer-Jung, M. L. Blaxter, W. Owen McMillan, and C. D. Jiggins, "ButterflyBase: a platform for lepidopteran genomics," Nucleic Acids Research, vol. 36, no. 1, supplement, pp. D582-D587, 2008.

[45] B. Joshi, K. Lee, D. L. Maeder, and R. Jagus, "Phylogenetic analysis of eIF4E-family members," BMC Evolutionary Biology, vol. 5, article 48, 2005.

[46] J. D. Thompson, D. G. Higgins, and T. J. Gibson, "CLUSTAL W: improving the sensitivity of progressive multiple sequence alignment through sequence weighting, position-specific gap penalties and weight matrix choice," Nucleic Acids Research, vol. 22, no. 22, pp. 4673-4680, 1994.

[47] D. G. Higgins, J. D. Thompson, and T. J. Gibson, "Using CLUSTAL for multiple sequence alignments," Methods in Enzymology, vol. 266, pp. 383-400, 1996.

[48] K. Tamura et al., "MEGA5: molecular evolutionary genetics analysis using maximum likelihood, evolutionary distance, and maximum parsimony methods," Molecular Biology and Evolution, vol. 28, no. 10, pp. 2731-2739, 2011.

[49] R. E. Rhoads, T. D. Dinkova, and R. Jagus, "Approaches for analyzing the differential activities and functions of eIF4E family members," Methods in Enzymology, vol. 429, pp. 261297, 2007.

[50] M. D. Adams, S. E. Celniker, R. A. Holt et al., "The genome sequence of Drosophila melanogaster," Science, vol. 287, no. 5461, pp. 2185-2195, 2000.

[51] D. K. Yeates, B. M. Wiegmann, G. W. Courtney, R. Meier, C. Lambkin, and T. Pape, "Phylogeny and systematics of Diptera: two decades of progress and prospects," Zootaxa, no. 1668, pp. 565-590, 2007.

[52] K. Tamura, S. Subramanian, and S. Kumar, "Temporal patterns of fruit fly (Drosophila) evolution revealed by mutation clocks," Molecular Biology and Evolution, vol. 21, no. 1, pp. 3644, 2004.

[53] B. M. Wiegmann, M. D. Trautwein, I. S. Winkler et al., "Episodic radiations in the fly tree of life," Proceedings of the National Academy of Sciences of the United States of America, vol. 108, no. 14, pp. 5690-5695, 2011.

[54] Q. Zhou and W. Wang, "On the origin and evolution of new genes-a genomic and experimental perspective," Journal of Genetics and Genomics, vol. 35, no. 11, pp. 639-648, 2008.

[55] Q. Zhou, G. Zhang, Y. Zhang et al., "On the origin of new genes in Drosophila," Genome Research, vol. 18, no. 9, pp. 1446-1455, 2008.

[56] E. Rom et al., "Cloning and characterization of 4E-HP, a novel mammalian eIF4E-related cap-binding protein," The Journal of Biological Chemistry, vol. 273, no. 21, pp. 13104-13109, 1998.

[57] K. A. Ruud, C. Kuhlow, D. J. Goss, and K. S. Browning, "Identification and characterization of a novel cap-binding protein from Arabidopsis thaliana," The Journal of Biological Chemistry, vol. 273, no. 17, pp. 10325-10330, 1998. 
[58] T. D. Dinkova, B. D. Keiper, N. L. Korneeva, E. J. Aamodt, and R. E. Rhoads, "Translation of a small subset of Caenorhabditis elegans mRNAs is dependent on a specific eukaryotic translation initiation factor 4E isoform," Molecular and Cellular Biology, vol. 25, no. 1, pp. 100-113, 2005.

[59] G. Hernández, M. Altmann, and P. Lasko, "Origins and evolution of the mechanisms regulating translation initiation in eukaryotes," Trends in Biochemical Sciences, vol. 35, no. 2, pp. 63-73, 2010. 

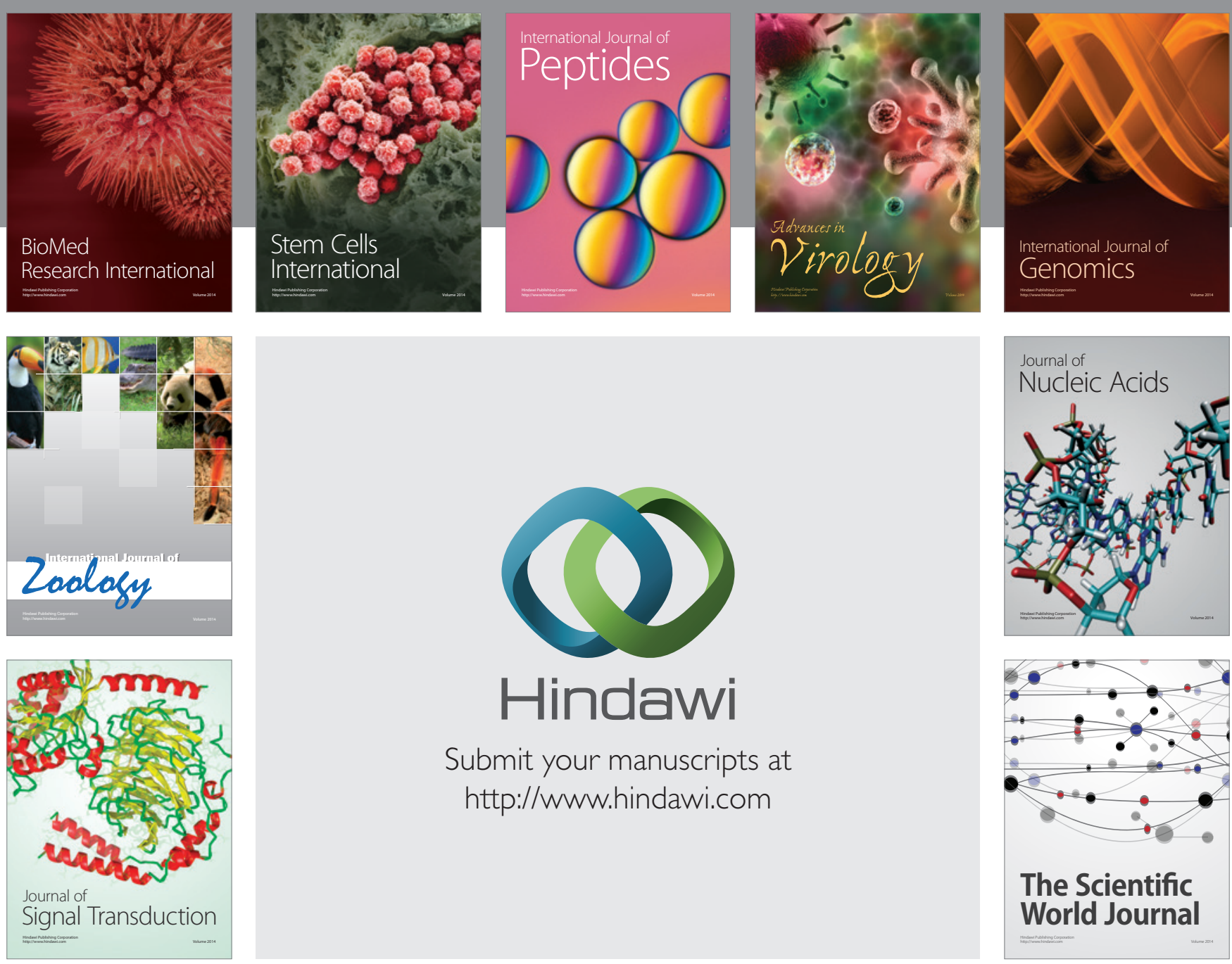

Submit your manuscripts at

http://www.hindawi.com
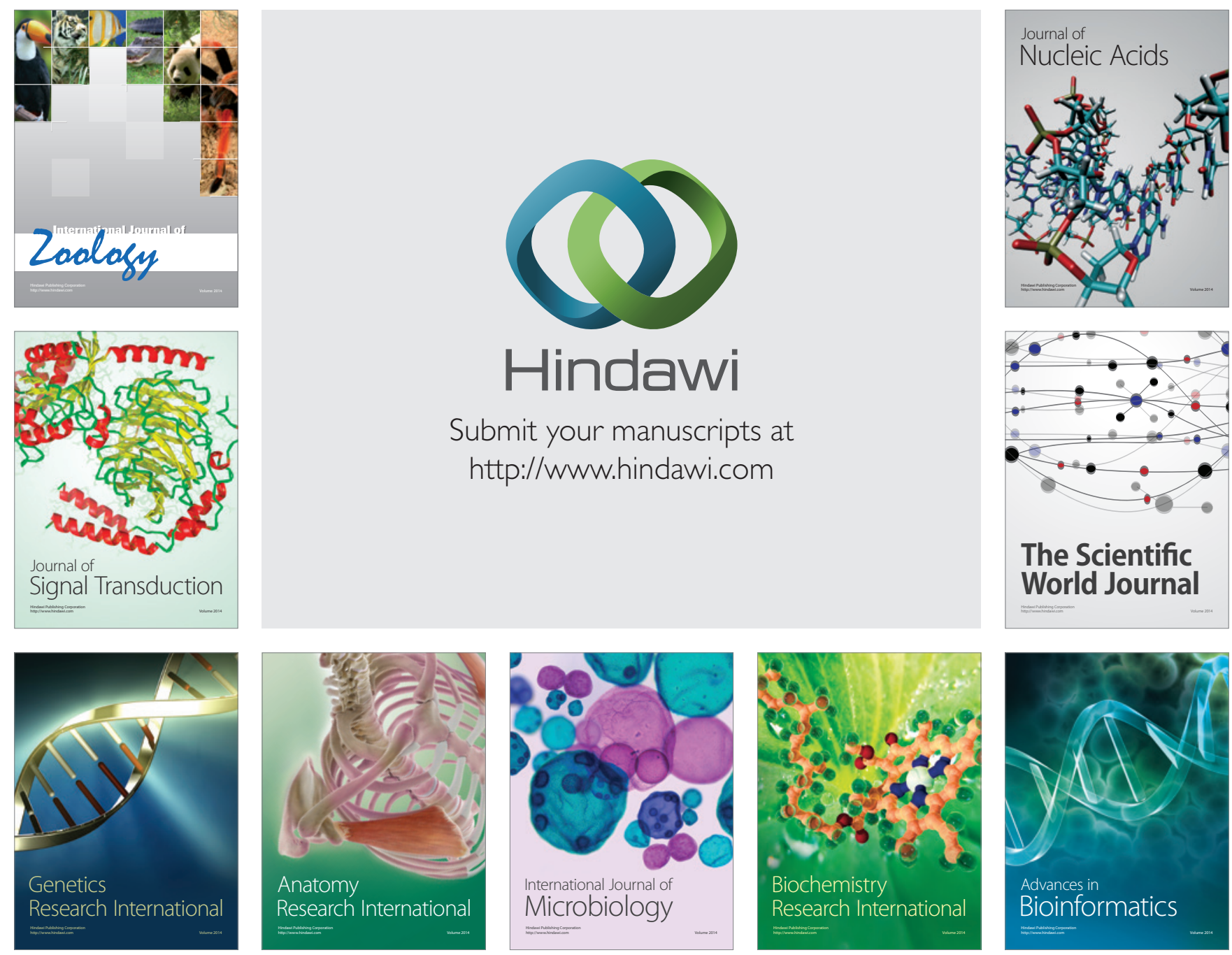

The Scientific World Journal
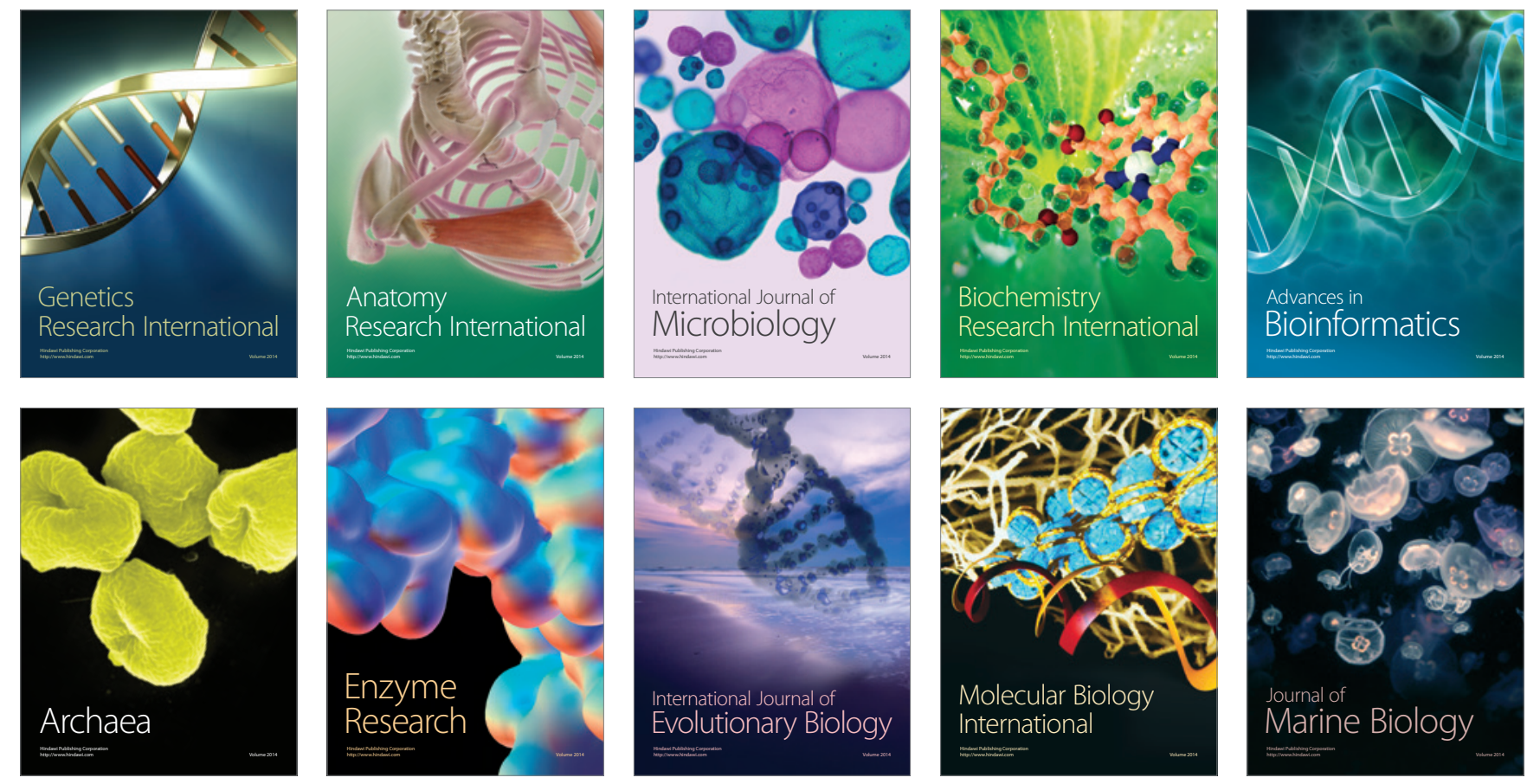